\title{
Silencing Marginalized Voices The Fragmentation of the Official Record
}

Librarians have good reason to be concerned about the potential loss of government information, but they can take action to help preserve the historical record.

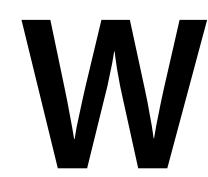
hen researching historical topics, government statistics are often viewed as the most reliable source of information, lending credibility to the researchers' arguments by providing documentary evidence of how society is changing. In investigating issues related to equity, diversity, and inclusion, these statistics serve as benchmarks for the progress (or lack thereof) on how historic injustices are being addressed. Therefore, it is imperative that the information be reliable, verifiable, and available. Accordingly, when any of those elements are in question, the citizenry should be gravely concerned, as it can be daunting to challenge the official record of our society, especially when marginalized voices are the ones being distorted, ignored, or erased. Let's review a few examples that illustrate this issue.

After January 20, 2017, the LGBTQ+ resources on the White House website formerly available under the previous administration could no longer be found. In the intervening months, no new information related to LGBTQ+ issues has been posted to the White House website. Though changes to the White House website are expected when new administrations take office, the disappearance of entire categories of information should be alarming to anyone concerned about preserving the public record. Thanks to the National Archives, the information from previous administrations' websites will be preserved, thus making it available to researchers for the foreseeable future. However, the archived website notes that external and internal links may no longer work, as pages previously available on other governmental websites may have also been removed by whichever administration is currently in office. In this case, the Internet Archive may have the missing pages on their website, but there's no guarantee that the desired information was captured, whether because pages were missed or snapshots missed important updates. There is also no guarantee that this nonprofit, nongovernmental website will continue to be available in the future. Without reliable access to government information, researchers will not be able to document what was available on governmental websites, and an important source of public policy data will be lost to future researchers.

\section{Martin Garnar}

Martin Garnar (mgarnar@uccs .edu) is Dean of the Kraemer Family Library at the University of Colorado Colorado Springs.

Reference \& User Services Quarterly, vol. 57, no. 3, pp. 193-95 (c) 2018 American Library Association. All rights reserved.

Permission granted to reproduce for nonprofit, educational use. 


\section{FEATURE}

Unfortunately, there is no easy way to monitor when information on government websites is changed or removed. Some websites, like that of the State Department, offer a subscription option to get updates on changes. However, other websites lack that option, so the only way to stay on top of changes is to visit websites on a regular basis to see when the information has been refreshed. Another option is to visit sites like the Internet Archive to compare different versions of a website over time to determine when information has changed, been replaced, or been removed. Given the Internet Archive's scope, it should not be surprising that archival snapshots of some websites can be few and far between, so this strategy may not work for specific web pages, especially for complex government sites with multiple layers of links and pages.

Thankfully, there have been a number of preservation efforts over the years specifically targeting government information. One of the earlier preservation efforts is the CyberCemetery at the University of North Texas. As noted in the collection's scope statement, "the CyberCemetery is an archive of government websites that have ceased operation (usually websites of defunct government agencies and commissions that have issued a final report)."1 Though a wide variety of topics are covered-including the website for the White House Initiative on Educational Excellence for Hispanic Americans - those related to issues of equity, diversity, and inclusion are in the minority.

Other projects target active government websites, including the Web-at-Risk project from 2005 to 2009 that culminated in the Web Archiving Service of the California Digital Library. ${ }^{2}$ Though that service still exists, they now use the subscription-based Archive-It service from the Internet Archive, thus further concentrating the preservation efforts in that one organization. The Internet Archive is also part of the End of Term Web Archive project, which was founded in 2008 to focus on preserving websites that may be "most atrisk of change or deletion at the end of the presidential term." Other partners include the University of North Texas and the California Digital Library. Those names should sound familiar, highlighting the fact that there are just a few organizations focused on preserving government information.

Though the project's founders agree that archiving of these websites should happen on an annual basis, ${ }^{4}$ their funding does not support increasing the frequency of collection, which is currently limited to presidential election years.

The good news is that other organizations are starting to get involved. Projects like the DataRefuge at the University of Pennsylvania will be crucial in the coming years to ensure that researchers, scientists, and historians have access to the government information they need to continue their work on topics like climate change. ${ }^{5}$ However, not all subject areas are covered by projects like these, so without someone championing the preservation of government information on specific topics, such as those focused on marginalized communities, it is possible that some information will be lost forever.
Thus far, we have reviewed some of the efforts aimed at preserving government websites. What happens when the information posted on government websites isn't accurate in the first place? Given the hostile tone of the current administration toward undocumented immigrants, it would not be surprising if any member of an immigrant community would hesitate to interact with government officials, thus calling into question the accuracy of any government surveys designed to collect information about our communities. Statistics about undocumented immigrants will be skewed away from the real numbers, giving false impressions about the efficacy of governmental initiatives, and researchers on all sides of the issue will have to depend on other potentially less reliable sources of information when trying to analyze the situation.

Though this may sound like a scenario based purely on speculation, a recent article in the Washington Post notes that efforts are underway to insert a question into the 2020 census asking respondents about their immigration status, which has never been done before and would likely have an impact on response rates from immigrant communities. ${ }^{6}$ The same article noted that a top contender for the deputy director of the US Census Bureau (the top administrative position related to the census) is an academic with no government experience.

In light of all of this, what's a librarian to do? In addition to actively lobbying our elected officials to preserve the historic reliability of government information and related collection practices, we should take on the tasks for which we are best suited as a profession: the preservation and organization of information. We should follow the lead of our colleagues at the University of North Texas and the California Digital Library by identifying at-risk government information on websites and developing a plan for archiving those sites. If we are at institutions that do not have the necessary resources to support large-scale archives, we can identify key documents and host them on our own websites. If that is not an option, we can volunteer to help with existing preservation projects. As noted on the End of Term Web Archive, volunteer nominators are vital to the success of the project and are "asked to contribute as much time and effort as they are able, whether it be a nomination of 1 website or 500 websites." "In his article in the Serials Librarian, Nick Szydlowski said it best:

The Internet Archive is a wonderful service, but librarians and archivists should not be lulled into thinking that the job of archiving the Web content that is most important to our patrons will be done by someone else. Institutions should identify content published on the Web that is important to their missions, and verify that that content is being archived adequately by an existing Web archive. Unless we really do discover a way to travel through time, we will only get one chance to preserve the materials needed by current and future researchers. ${ }^{8}$ 
As marginalized groups are often disproportionately impacted by issues that should be the concern of the federal government-whether it be environmental concerns, educational policy, or protection of civil rights-reliable access to government information will continue to be paramount for those fighting for equity, diversity, and inclusion.

\section{References}

1. "CyberCemetery," University of North Texas, accessed December 4, 2017, https://digital.library.unt.edu/explore/collections /GDCC/.

2. "The Web-at-Risk: Preserving Our Nation's Digital Cultural Heritage," California Digital Library, accessed December 4, 2017, http://www.cdlib.org/services/uc3/partners/webatrisk.html.
3. "End of Term 2016," End of Term Web Archive, accessed December 4, 2017, http://eotarchive.cdlib.org/2016.html.

4. Tracy Seneca, Abbie Grotke, Cathy Nelson Hartman, and Kris Carpenter, "It Takes a Village to Save the Web," DttP: A Quarterly Journal of Government Information Practice and Perspective 40, no. 1 (Spring 2012): 16-23.

5. "About," DataRefuge, accessed December 4, 2017, https://www .datarefuge.org/about.

6. Paul Waldman, "Trump's New Census Bureau Hire Could Give the GOP a Big Boost," Washington Post, November 21, 2017, https://www.washingtonpost.com/blogs/plum-line/wp/2017 /11/21/trumps-new-census-bureau-hire-could-give-the-gop-a-big -boost/?utm_term=.9fe89b101485.

7. "End of Term 2016."

8. Nick Szydlowski, "Archiving the Web: It's Going to Have to Be a Group Effort," Serials Librarian 59 (2010): 35-39. 